\title{
A Case of Osteosarcoma in a Patient With Pycnodysostosis
}

\author{
Natasha Cortisse, MD, ${ }^{*}$ Patricia Forget, MD, ${ }^{*}$ Marie F. Dresse, MD,* \\ Benoit Florkin, MD, ${ }^{*}$ Eric Mascard, MD, † Jean M. Guinebretière, MD, $\neq$ \\ Laurence Brugières, $M D, \S$ and Claire Hoyoux, $M D^{*}$
}

\begin{abstract}
Summary: Pycnodysostosis is a rare sclerosing bone dystrophy. The main clinical features are short stature and oral and maxillofacial abnormalities such as a large head, a small and underdeveloped face with prominent nose and eyes, irregular dentition, small hands and feet with dystrophic nails, and trunk deformities such as scoliosis. The differential diagnosis is established with other skeletal dysplasias such as osteopetrosis, cleidocranial dysplasia, and idiopathic acroosteolysis. Since its first description in 1962 by Maroteaux and Lamy, about 100 cases have been published, some of these with uncommon features. We describe the case of a 22-year-old European man with pycnodysostosis who developed a chondroblastic osteosarcoma of the right femur. No case of bone cancer in this sclerosing bone disease had been described so far.
\end{abstract}

Key Words: pediatric oncology, pycnodysostosis, oteosarcoma

( J Pediatr Hematol Oncol 2012;34:545-547)

Pyctic ycnodysostosis meaning "thick defective bones" (from the Greek pycnos = dense, dys = defective, and stosis $=$ of bone) is a rare sclerosing bone dystrophy. It was first described in 1962 by Maroteaux and Lamy as a variant of osteopetrosis (Albers-Schönberg disease). ${ }^{1}$ It is an autosomal recessive disorder, the main clinical features of which are short stature at all ages, large head with frontal and parietal bossing, delayed closure of the fontanelles with wide, unossified cranial sutures, a small and underdeveloped face, with a beaked nose, prominent eyes, obtuse mandibular angle, a high grooved palate, and irregular dentition. Hands and feet are short, broad, with short terminal phalanges and dystrophic lenticulate nails. The acromial end of the clavicles is hypoplastic,s and trunk deformities such as scoliosis, increased lumbar lordosis, or kyphosis can be seen..$^{24}$

Usually diagnosed at an early age, the diagnosis is sometimes late, made because of bone fracture due to severe bone fragility resulting from increased bone density. ${ }^{5}$ The differential diagnosis is to be made with other skeletal dysplasias such as osteopetrosis, cleidocranial dysplasia, and idiopathic acro-osteolysis.

No case of bone cancer in this sclerosing bone disease has been described so far. We report the first case of

Received for publication March 13, 2011; accepted February 1, 2012. From the *Department of Pediatrics, Division of Hematology/Oncology, Clinique CHR de la Citadelle, Liège, Belgium; †Department of Orthopaedic Surgery, Clinique ARAGO, Paris; $\$$ Department of Pathology, Centre René-Huguenin, Sain Cloud; and §Department of Pathology, Institut Gustave Roussy, Villejuif, France.

The authors declare no conflict of interest.

Reprints: Claire Hoyoux, MD, Department of Pediatrics, Division of Hematology/Oncology, Clinique CHR de la Citadelle, Bd 12ème de Ligne 1, B-4000 Liège, Belgium (e-mail: claire.hoyoux@ chrcitadelle.be)

Copyright (C) 2012 by Lippincott Williams \& Wilkins chondroblastic osteosarcoma (OS) in a patient with pycnodysostosis.

\section{CASE REPORT}

We present the case of a young man diagnosed with pycnodysostosis during his first year of life. Born to consanguineous parents and adopted at the age of 3 months, he showed the main clinical features as presented before, such as short stature, a large head with a small and underdeveloped face, and small hands and feet with dystrophic nails (Fig. 1). He also had a cleft palate (usually not described in pycnodysostosis). Diagnosis was based on radiographs that showed typical signs of pycnodysostosis (Fig. 2).

This young man was referred to our department with a 7-month history of pain in his upper right leg. One month before diagnosis he started to limp and a swelling appeared. X-ray showed a large heavily calcified mass on the upper part of his right femur; magnetic resonance imaging scan showed a large tumor on the right diaphysis of the femur (Fig. 3). Biopsy of the lesion confirmed the diagnosis of chondroblastic OS (Fig. 4). No metastasis was found.

$\mathrm{He}$ was treated according to the French protocol osteosarcoma 2006. Surgery consists of resection-reconstruction of the bone. He has been in first complete remission since $>2$ years after the end of treatment.

\section{DISCUSSION}

Pycnodysostosis, an inherited autosomal recessive disorder, is due to a genetic defect located on chromosome 1q21. Different mutations ${ }^{6,7}$ located on this chromosome are responsible for changes in a lysosomal cysteine protease, cathepsin K. This protease, expressed in osteoclasts, is a key enzyme in the degradation of bone matrix proteins. Because of the reduced expression of cathepsin $\mathrm{K}$ in the osteoclasts, these cells are not able to remove the organic matrix ( $95 \%$ of which is collagen type 1$)$. This osteoclastic dysfunction results in reduced bone resorption. Bone resorption in pycnodysostosis is defective but not completely inhibited, as there is a nonosteoclastic pathway for degradation of bone matrix.

Other bone-lining cells containing matrix metalloproteinase activities are able to degrade demineralized collagen left over from osteoclasts. ${ }^{8,9}$ However, the collagen breakdown products resulting from cathepsin $\mathrm{K}$ activity are different from those resulting from the alternative proteinases, which suggests that the microenvironment of bone is altered. ${ }^{10}$ Furthermore, osteoblastic function and bone formation seem to be altered as bone formation and bone resorption are closely linked and the dysfunction of one can imbalance the other. The abnormal bone turnover due to cathepsin $\mathrm{K}$ deficiency in patients with pycnodysostosis results in osteosclerosis and a highly disturbed bone architecture that cannot adapt to mechanical stress. This leads to a highly disordered lamellar structure and therefore an increased susceptibility to fractures. ${ }^{11}$ Fractures are 

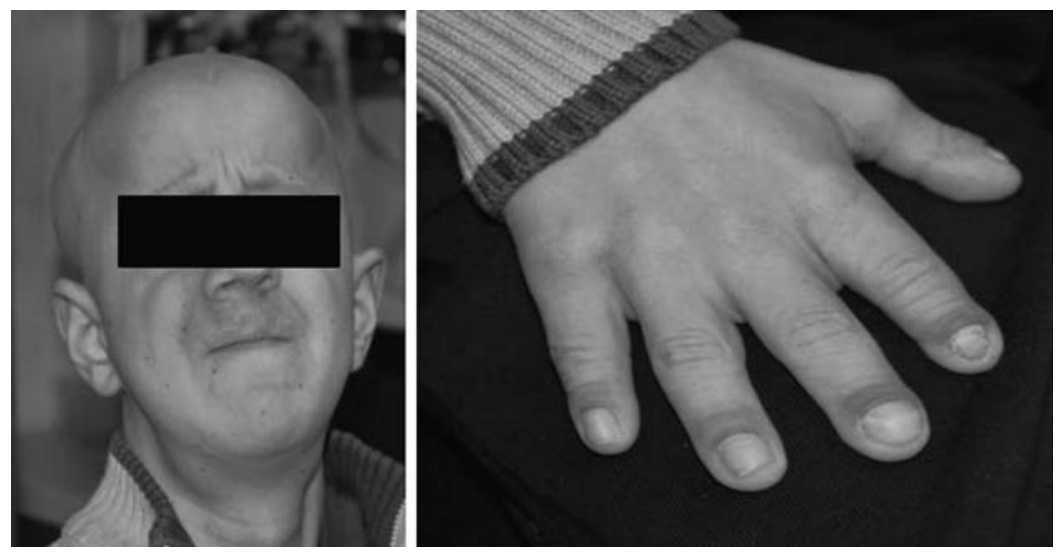

FIGURE 1. Our patient aged 22 years, his hand with short fingers.
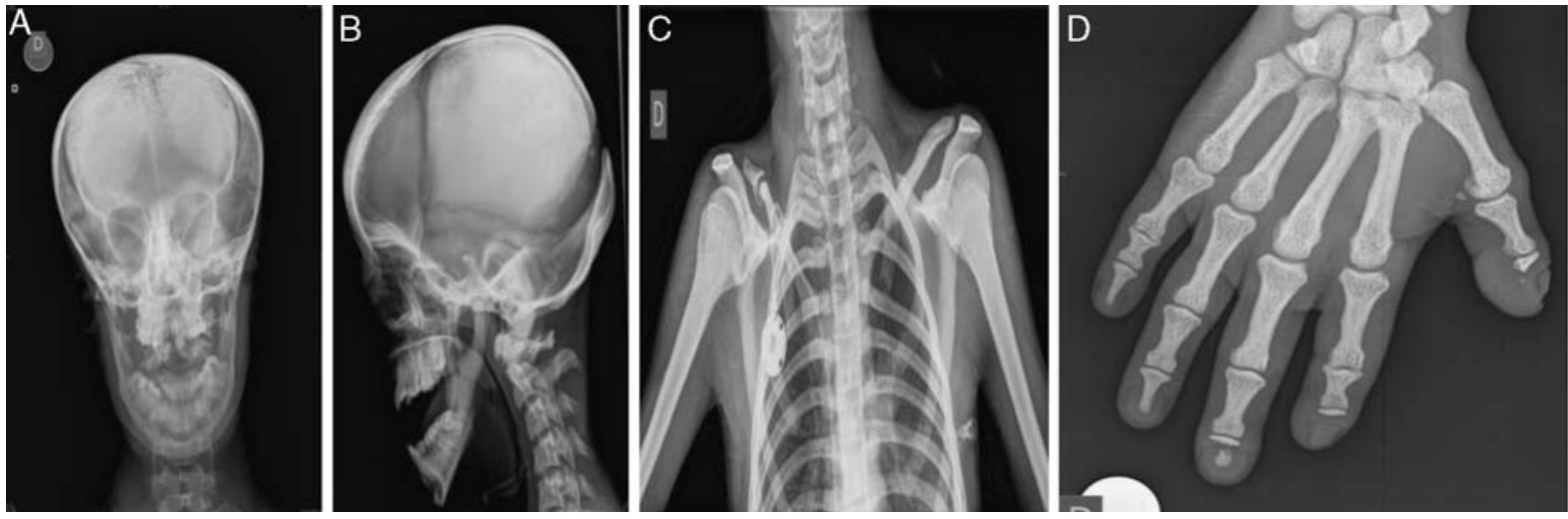

FIGURE 2. A and B, Radiograph of the skull: enlarged sutures and presence of wormian bones at the lambdoid suture, no mandibular angle. C, Radiograph of the rib cage: large and densified ribs, the distal end of the right clavicle is partly missing with congenital pseudarthrosis. D, Radiograph of the hands: increased density with resorption of the terminal phalanges in fingers 1 to 3 .

A

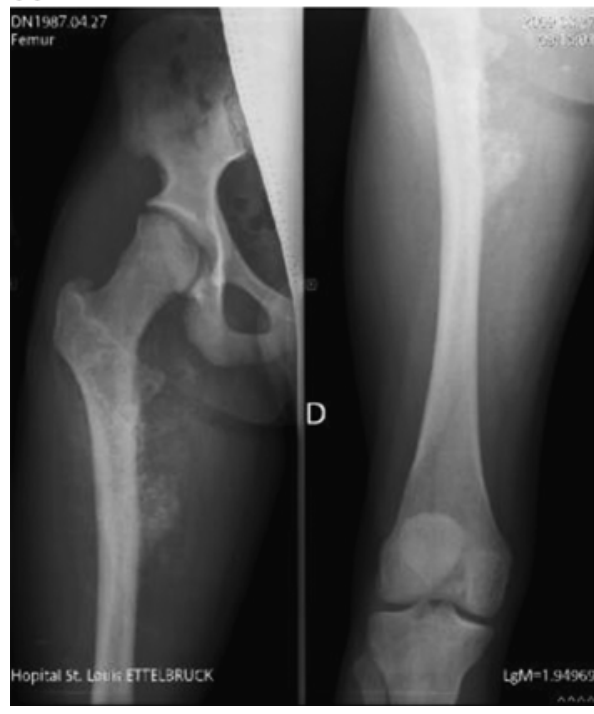

B

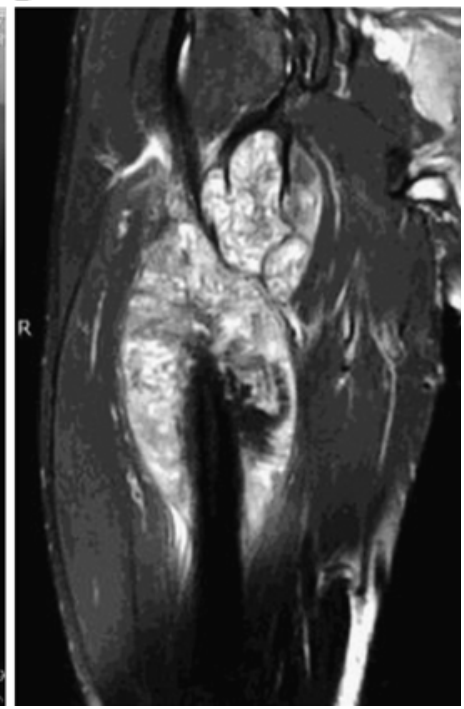

FIGURE 3. A, Radiograph of the right femur: increased density of the bone and a large calcified mass. B, Magnetic resonance imaging of the right femur: large tumor $(25 \times 9.3 \times 8.2 \mathrm{~cm})$. 


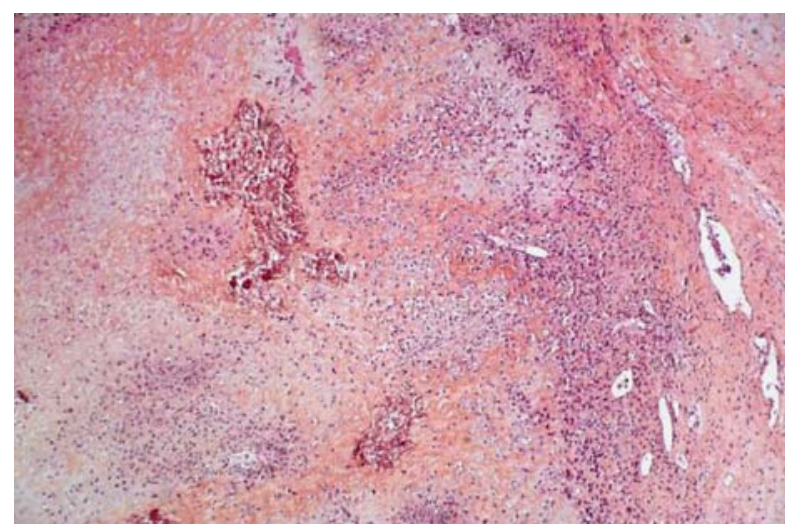

FIGURE 4. Pathology of the tumor (HES $\times 50$ ): the tumor is cellular, mainly composed of an immature chondroblastic component, focally necrotic, and calcified with minimal osteoblastic areas.

frequent in this disease with an abnormal bone turnover, but no case of malignant lesion has been described so far.

OS is a malignant mesenchymal sarcoma characterized by the direct formation of bone or osteoid by tumors cells. OS is subclassified on the basis of the histologic characteristics of the cells: when the product of chondroid matrix is predominant, the tumor is classified as a chondroblastic OS. ${ }^{12}$ The metaphyses of long tubular bones are mostly involved: distal femur $(50 \%)$, proximal tibia $(25 \%)$, proximal humerus $(10 \%)$, and proximal fibula $(5 \%){ }^{12,13}$

The etiology of OS remains unknown. Rapid bone growth seems to predispose individuals to OS as suggested by the increased incidence during adolescent growth spurt and the typical location of this cancer in the metaphyseal area. The only known environmental factor is radiation. Bone dysplasias, including Paget disease, fibrous dysplasias, enchondromatosis, and hereditary multiple exostoses, are risk factors. Some genetic predispositions have been identified, such as the constitutional mutation of the retinoblastoma gene (germline $\mathrm{Rb}$ ), the Li Fraumeni syndrome (germline p53 mutation), and the autosomic recessive Rothmund-Thomson syndrome (association of congenital bone defects, hair and skin dysplasias, hypogonadism, and cataracts). ${ }^{13}$ No clinical association with pycnodysostosis has been described before.

\section{CONCLUSIONS}

We describe the first case of chondroblastic OS in a young man suffering from pycnodysostosis.

\section{REFERENCES}

1. Maroteaux P, Lamy M. Pyknodysostosis. Presse Med. 1962;70:999-1002.

2. Maroteaux P. The osteochondrodysplasias. In: Maroteaux P, ed. Bone Diseases of Children. Philadelphia: JB Lippincott Co; 1979:116.

3. Maroteaux P, Lamy M. 2 cases of a condensing osseous disease: pycnodysostosis. Arch Fr Pediatr. 1962;19:267-274.

4. Maroteaux $\mathrm{P}$, Lamy $\mathrm{M}$. The malady of Toulouse-Lautrec. JAMA. 1965;191:715-717.

5. Alves-Pereira D, Berini-Aytés L, Gay-Escoda C. Pycnodysostosis. a report of 3 clinical cases. Med Oral Patol Oral Cir Bucal. 2008;13:E633-E635.

6. Hou WS, Bromme D, Zhao Y, et al. Characterization of novel cathepsin $\mathrm{K}$ mutations in the pro and mature polypeptide regions causing pycnodysostosis. J Clin Invest. 1999;03:31-38.

7. Fujita Y, Nakata K, Yasui N, et al. Novel mutations of the cathepsin $\mathrm{K}$ gene in patients with pycnodysostosis and their characterization. J Clin Endocrinol Metab. 2000;85:425-431.

8. Sassi ML, Eriksen H, Risteli L, et al. Immunochemical characterization of assay for carboxyterminal telopeptide of human type I collagen: loss of antigenicity by treatment with cathepsin K. Bone. 2000;26:367-373.

9. Everts V, Delaisse JM, Korpel W, et al. The bone lining cell: its role in cleaning Howships lacunae and initiating bone formation. J Bone Miner Res. 2002;17:77-90.

10. Garnero P, Ferreras M, Karsdal MA, et al. Collagen fragments ICTP and CTX reveal distinct enzymatic pathways of bone collagen degradation. J Bone Miner Res. 2003;18:859-867.

11. Nadja Fratzl-Zelman, Angelika Valenta, Paul Roschger, et al. Clinical case seminar: decreased bone turnover and deterioration of bone structure in two cases of pycnodysostosis. $J$ Clin Endocrinol Metab. 2004;89:1538-1547.

12. Vander Griend RA. Osteosarcoma and its variants. Orthop Clin North Am. 1996;27:575-581.

13. Eyre R, Feltbower RG, Mubwandarikwa E, et al. Epidemiology of bone tumours in children and young adults. Pediatr Blood Cancer. 2009;53:941-952. 